\begin{tabular}{|l|l|l||}
\hline \multicolumn{2}{|c|}{ PublisherInfo } \\
\hline \hline PublisherName & $:$ & BioMed Central \\
\hline \hline PublisherLocation & $:$ & London \\
\hline \hline PublisherImprintName & $:$ & BioMed Central \\
\hline \hline
\end{tabular}

\title{
Interfering with RNA interference
}

\begin{tabular}{|l|l|l||}
\hline \multicolumn{2}{|c|}{ ArticleInfo } \\
\hline \hline ArticleID & $:$ & 4323 \\
\hline \hline ArticleDOI & $:$ & $10.1186 /$ gb-2002-3-3-reports0013 \\
\hline \hline ArticleCitationID & $:$ & reports0013 \\
\hline \hline ArticleSequenceNumber & $:$ & 18 \\
\hline \hline ArticleCategory & $:$ & Paper report \\
\hline \hline ArticleFirstPage & $:$ & 1 \\
\hline \hline ArticleLastPage & $:$ & 4 \\
\hline \hline & & RegistrationDate : 2001-12-11 \\
ArticleHistory & $:$ & Received \\
& $:$ 2001-12-11 \\
\hline \hline ArticleCopyright & $:$ & BioMed Central Ltd2002 \\
\hline \hline ArticleGrants & $:$ & \\
\hline \hline
\end{tabular}




\begin{tabular}{|l|l|l|}
\hline ArticleContext & $:$ & 130593333 \\
\hline
\end{tabular}

\section{Nektarios Tavernarakis}

\section{Abstract}

Adenine deamination in double-stranded RNA by specific adenine deaminases efficiently blocks RNA interference in vitro

\section{Significance and context}

Since it was first described a few years ago, in the nematode Caenorhabditis elegans, double-stranded (ds) RNA interference (RNAi) has been the subject of intense study. As a result, we now understand many mechanistic aspects of RNAi and methodologies have been developed for using it to 'knock down' specific gene activity in many organisms. RNAi is not only a fascinating biological phenomenon but also a valuable modern research tool.

In RNAi, long dsRNAs are initially processed by RNase III (the Dicer enzyme in Drosophila) to generate small interfering RNAs (siRNAs), 21-23 nucleotides long, that then drive specific nuclease complexes to degrade the cognate mRNAs. This process is thought to comprise part of cellular defenses against viruses and transposable elements. An additional line of defense may be adenine deaminases that act specifically on dsRNA (ADARs). These edit dsRNA by converting adenine (A) to inosine (I).

Hyperediting of dsRNA by ADARs would not only generate many missense mutations, thus altering the coding capacity of RNA (I is seen as guanine $(\mathrm{G})$, not A, during translation), but would also

significantly affect dsRNA structure by altering proper A-U base pairing to I-U. Such modified dsRNAs could then be targeted for degradation and might constitute poor initiators of RNAi. On the other hand, processing of long dsRNAs to siRNAs by the RNAi machinery would render them poor substrates for deamination by ADARs, as siRNAs are too short to be deaminated. Paradoxically, even though RNAi and ADARs seem to be working towards the same end (cell defense against spurious RNAs) they can potentially antagonize each other. But is this so?

\section{Key results}

Scadden and Smith now present evidence that, at least in vitro, ADAR activity can effectively block RNAi. In a Drosophila extract that is active for RNAi, they show that long dsRNAs, previously deaminated to about $50 \%$ by ADAR, will not trigger RNAi-mediated degradation of cognate mRNAs. Even at lower levels of deamination, RNAi is inhibited in proportion to the extent of hyperediting. To 
determine how deamination reduces interference and which step(s) in RNAi is affected, the authors examined the conversion of long, deaminated dsRNA to siRNAs in their in vitro system and found that $43 \%$ deamination of the input dsRNA is sufficient completely to abolish generation of siRNAs. It appears that hyperedited dsRNAs are poor substrates for RNAse III. With a lower level of editing, siRNAs are generated, albeit less efficiently.

In the case of moderate editing, siRNAs could either originate exclusively from non-edited dsRNA, in which case they would not contain I, or they could contain I if they were the product of processing edited dsRNA. The authors show that when moderately deaminated dsRNA is used, the siRNAs generated do contain I, in amounts proportional to the extent of deamination of the input dsRNA. This indicates that RNase III (Dicer in this case) does not discriminate between edited and non-edited sequences of dsRNA. It is conceivable that I-containing siRNAs might have a much reduced ability to drive specific degradation of cognate mRNAs. This would suggest that ADAR activity impacts on RNAi at two levels: first, reduced processing of deaminated dsRNAs to siRNAs; and second, reduced effectiveness of I-containing siRNAs.

\section{Conclusions}

The authors conclude that antagonism between ADARs and RNAi does exist in their in vitro set-up and can be manifested at least at the level of siRNA generation. The same experimental methodology can be used to investigate the effectiveness of deaminated siRNAs in exerting degradation of cognate mRNA. The authors note that for antagonism to occur in vivo, ADARs would have to be active in the vicinity of the RNAi machinery. This requires overlapping temporal and spatial expression of ADARs and RNAi machinery components, as well as similar subcellular localization. An interesting peculiarity that might be attributable to antagonism between ADARs and RNAi is the relative ineffectiveness of RNAi in the nervous system and other specialized tissues of $C$. elegans. ADARs are known to be highly expressed in the nervous system and this may, in part, contribute to the limited ability of RNAi to target neuronal genes.

\section{Reporter's comments}

By demonstrating that hyperediting of dsRNA can efficiently antagonize RNAi in vitro, Scadden and Smith provoke the interesting question of what, if any, is the in vivo role of this clash between processes that presumably serve a similar purpose. To address this question, antagonism needs first to be shown in vivo. Ongoing genetic screens in C. elegans for mutants that allow efficient RNAi of nervous system genes are expected to shed light on the molecular mechanisms that render this tissue relatively refractory to RNAi. ADAR-related genes may well turn up in these screens. A quicker route might be to directly knock out nematode ADAR-like genes (the closest candidate is the predicted open reading frame T20H4.4), and then test for neuronal susceptibility to RNAi. 


\section{Table of links}

EMBO Reports

\section{References}

1. Scadden ADJ, Smith CWJ: RNAi is antagonized by $\mathrm{A} \rightarrow \mathrm{I}$ hyperediting. EMBO Rep. 2001, 2 :

1107-1111. 1469-3178

This PDF file was created after publication. 